August 1999 • NREL/CP-520-26364

\title{
The Use of Electron Channeling Patterns for Process Optimization of Low- Temperature Epitaxial Silicon Using Hot-Wire Chemical Vapor Deposition
}

R. Matson, J. Thiesen, K.M. Jones, R. Crandall, E. Iwaniczko, and H. Mahan

Presented at the Materials Research Society's Spring Conference San Francisco, California April 6-10, 1999

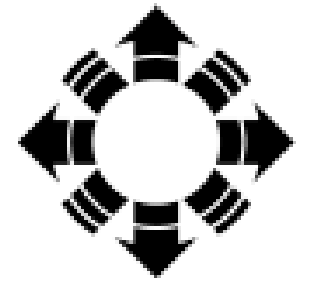

NPEI

National Renewable Energy Laboratory

1617 Cole Boulevard

Golden, Colorado 80401-3393

NREL is a U.S. Department of Energy Laboratory

Operated by Midwest Research Institute $\bullet$ Battelle $\bullet$ Bechtel

Contract No. DE-AC36-98-G010337 


\section{NOTICE}

This report was prepared as an account of work sponsored by an agency of the United States government. Neither the United States government nor any agency thereof, nor any of their employees, makes any warranty, express or implied, or assumes any legal liability or responsibility for the accuracy, completeness, or usefulness of any information, apparatus, product, or process disclosed, or represents that its use would not infringe privately owned rights. Reference herein to any specific commercial product, process, or service by trade name, trademark, manufacturer, or otherwise does not necessarily constitute or imply its endorsement, recommendation, or favoring by the United States government or any agency thereof. The views and opinions of authors expressed herein do not necessarily state or reflect those of the United States government or any agency thereof.

Available to DOE and DOE contractors from:

Office of Scientific and Technical Information (OSTI)

P.O. Box 62

Oak Ridge, TN 37831

Prices available by calling 423-576-8401

Available to the public from:

National Technical Information Service (NTIS)

U.S. Department of Commerce

5285 Port Royal Road

Springfield, VA 22161

$703-605-6000$ or $800-553-6847$

or

DOE Information Bridge

http://www.doe.gov/bridge/home.html

Printed on paper containing at least $50 \%$ wastepaper, including $20 \%$ postconsumer waste 


\title{
THE USE OF ELECTRON CHANNELING PATTERNS FOR PROCESS OPTIMIZATION OF LOW-TEMPERATURE EPITAXIAL SILICON USING HOT-WIRE CHEMICAL VAPOR DEPOSITION
}

\author{
R. MATSON, J. THIESEN*, K.M. JONES, R. CRANDALL, E. IWANICZKO, H. MAHAN \\ National Renewable Energy Laboratory (NREL), 1617 Cole Blvd., Golden, CO, 80401 \\ *Also of the Dept. of Electrical Eng., University of Colorado, Boulder, CO
}

\begin{abstract}
We demonstrate the first reported use of electron channeling patterns (ECPs) as a response for a statistical design of experiments process-optimization for epitaxial silicon. In an effort to fully characterize the new hot-wire chemical vapor deposition (HWCVD) method of epitaxial growth recently discovered at NREL, a large number of parameters with widely varying values needed to be considered. To accomplish this, we used the statistical design of experiments method. This technique allows one to limit the number of sample points necessary to evaluate a given parameter space. In this work we demonstrate how ECPs can effectively be used to optimize the process space as well as to quickly and economically provide the process engineer with absolutely key information.
\end{abstract}

\section{INTRODUCTION}

The recognized importance of low-temperature Si epitaxy is clearly reflected by the effort put forth by many distinguished researchers and laboratories. A good low-temperature epitaxial (LTE) process would simplify the process engineering of deep submicron CMOS technology, SiGe alloy devices, and a wide range of novel devices. Recently, it was discovered that LTE Si can be grown via the HWCVD method. In an effort to understand and exploit this discovery, we have attempted to optimize the large nonlinear parameter space associated with this growth technique.

HWCVD is a gas-source growth technique, in which feed gas is decomposed on a hot filament. There are four basic parameters that control growth in this technique: pressure, substrate temperature, flow rate, and filament temperature. Ambient pressures may vary from 5-100 mTorr. Substrate temperatures may vary from $195^{\circ}$ to $450^{\circ} \mathrm{C}$. Flow rates of interest are between 5 and $90 \mathrm{sccm}$, and filament temperatures are between $1700^{\circ}$ and $2100^{\circ} \mathrm{C}$. The upper and lower ranges of the filament temperature are set by the points at which $\mathrm{W}$ begins to evaporate and the point at which the filament alloys with Si so badly that it is no longer of any practical use. These are the fundamental parameters of HWCVD. However, gas composition may be considered as a fifth parameter. In this case, we would be interested in the effects of He and $\mathrm{H}$ dilution on the growth of epitaxial layers with this technique.

For cases where process optimization involves a large number of process variables, such as HWCVD, optimization by varying one parameter at a time can easily become resource intensive. Instead of real optimization, what usually occurs is that a good operating point is found either by accident or intuitive insight, and work proceeds from there. But another technique widely employed in both industry and academic research, design of experiments (DOEs) can allow for real optimization. This technique has an interesting history and has led to a great number of improvements in processes and product reliability. ${ }^{1,2}$

To appreciate the usefulness of this approach, consider the HWCVD problem. We know from the work of others ${ }^{3-5}$ that all of the process variables are important to the growth of a-Si:H. This 
means that any useful study of Si homoepitaxy using HWCVD should assume the same. For process variables with the ranges indicated above we can imagine performing experiments at increments of $5 \mathrm{mT}$ Trr for pressure, $5 \mathrm{sccm}$ for flow, $100^{\circ} \mathrm{C}$ for filament temperature, and $50^{\circ} \mathrm{C}$ for substrate temperature. In this scheme, we would perform more than 1600 experiments to map out this parameter space. On the other hand, with the DOE method we can approximate this same result with 32 experiments, can consider a mixture of gases, and even further leverage our work by simultaneously depositing on a variety of substrates, varying both substrate dopant type and quantity.

The statistical DOE methodology is described quite thoroughly elsewhere, ${ }^{1,2}$ and here we will present only a brief overview. Let us consider a process $\mathrm{P}$, having $\mathrm{x}$ number of parameters $p_{i}$, in which $\mathrm{i}$ varies from 1 to $\mathrm{x}$. Let us then assume that each parameter can affect the outcome of $P$ in some measurable way. The response of a given $P$ is $R_{p}$. We assume that there is one $R_{p}$ desired above all others, which we call the optimal response, $\mathrm{R}_{0}$. Now imagine an $\mathrm{x}$-dimensional surface whose edges are defined by the range of the $p_{i} \mathrm{~s}$. For example, if $\mathrm{x}=3$, we would construct a box whose sides ranged over each parameter and whose eight corners represented combinations of the maximum and minimum extent of our $p_{i} \mathrm{~s}$. Let us then measure $\mathrm{R}_{\mathrm{p}}$ at the vertices of our box, at the midpoints of the edges of our box, the centers of each face, and finally the center of our box. This set of $\mathrm{R}_{\mathrm{p}} \mathrm{s}$, along with the points $\left\{p_{1}, p_{2}, \ldots p_{i}, \ldots p_{x}\right\}$ from our box, are points in an $x+1$ dimensional space, which we can fit to a mathematical expression. This mathematical expression or model is a surface in this $x+1$ dimensional space. The closeness of the fit, or statistical validity, of the model is determined by a regression analysis. The validity of the regression analysis can be verified with the use of replicate experiments and measurements. These replicates determine if the process and the experimentalist's work are reproducible enough to predict an outcome. If in the end the model is determined to be valid, a surface can be mapped and $R_{0}$ determined. If the response surface is relatively smooth and surface features vary slowly, we get a predictive model that is continuous over the entire range of the parameters studied.

Although the above is an oversimplification, and techniques vary from design to design and from implementation to implementation, the main ideas do not change much from these simple concepts. The major problem with the application of this methodology to epitaxial growth is finding an effective quantitative analytical tool with which to measure changes in film properties with changes in parameters, or the response, a tool that is both timely and nondestructive. Both transmission electron microscopy (TEM) and secondary ion spectrometry (SIMS) are time consuming, capital intensive, destructive, and seldom available for the time needed to study large matrices of samples. Defect etching and device fabrication are faster, but are also destructive. Also, the study of electronic properties via devices can be ambiguous when trying to determine the cause of poor responses. We have found that electron channeling (EC) is a rapid, reliable, and, at least, semi-quantitative measure of the quality of a film's crystallinity - which we will use to measure the response of a given configuration of variables.

Electron channeling is a surface-sensitive technique based on the Bragg diffraction of the primary electrons striking a sample within an SEM. The basic idea behind the EC used here is that a collimated beam of electrons is rocked about a point wherein the electrons move in and out of Bragg diffraction conditions, thereby giving rise to an ECP, which reveals crystalline type, orientation, and, quality. Information in and ECP comes from approximately the top $100 \AA$ or so of material. Hence, if the top surface of the material is crystalline and well organized, one gets a well-defined ECP see Fig. 1-(Reference ECP). On the other hand, if the near surface is amorphous, poorly organized, or defect laden, the ECP will be correspondingly poor. The "crystalline quality scale," used as a measure of the quality of the deposited Si films, is 
demonstrated in Fig. 1. A rating of zero corresponded to no discernible pattern, and a rating of 10 corresponded to no discernible difference between the ECP obtained from the deposited film and bare $\mathrm{Si}$ wafer, with all other values and qualities falling between these. The assessment between authors and the agreement between replicate experiments was surprisingly consistent. It is also important to note that on the order of 20 samples can be loaded into the SEM at once, and an ECP could be acquired at least every 5 minutes, so the evaluation process can be quite quick.

\section{EXPERIMENTAL}

Sample preparation and the mechanics of film growth are described elsewhere ${ }^{6,7}$ Experimental design and analysis were carried out using the CARD DOE software package from S-Matrix. ${ }^{8}$ Using this technique, we have studied the effects of varying pressure, substrate temperature, filament temperature, flow rate, He dilution, and $\mathrm{H}$ dilution. In various optimizations, substrate temperatures were varied from $200^{\circ}$ to $450^{\circ} \mathrm{C}$, filament temperatures were varied from $1700^{\circ}$ to $2100^{\circ} \mathrm{C}$, flow rates from 5 to $40 \mathrm{sccm}$, and pressures from 5 to $40 \mathrm{mTorr}$.

In the immediate study, parameters were varied as indicated in Table 1 while nominally

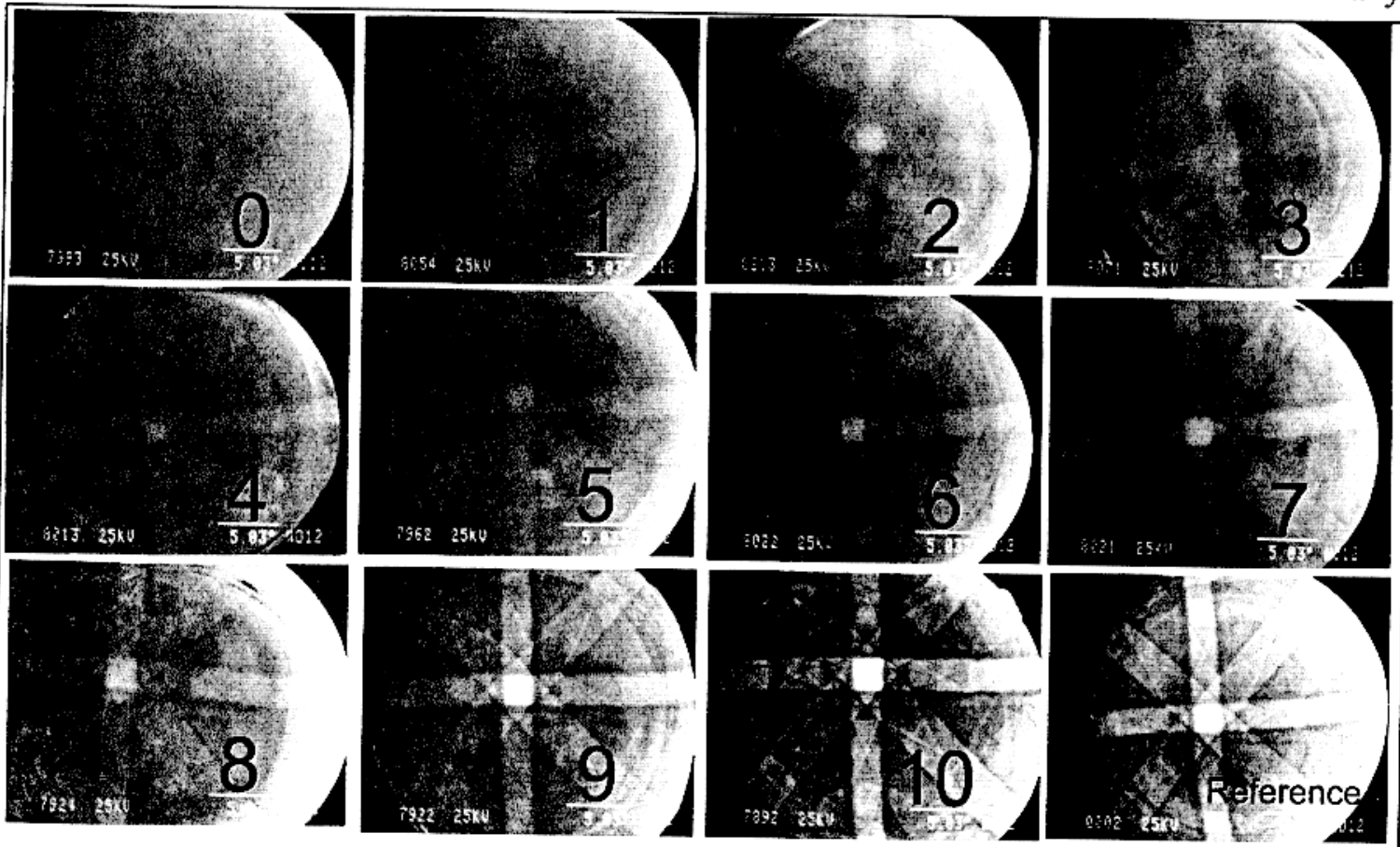

Figure 1 - We see electron channeling patterns scaled from 1-10. The reference, a channeling pattern from a bare piece of lightly doped $\mathrm{n}$-lype $\mathrm{Si}$, has a value of 10 and is shown in the lower right hand corner. The value of zero indicates no observed pattern and is shown in the upper left corner.

intrinsic films were grown on both heavily $\left(\sim 10^{18}\right)$ and lightly $\left(\sim 10^{15}\right)$ doped substrates. The substrate temp is labeled Temp, the flow rate in sccm is labeled Flow, and filament current in amps is labeled Fil. Cur. The filament current is linearly proportional to temperature and is our most reliable quantification for this important parameter. The measured ECP response of the samples is indicated in the column labeled Qual. Quality was appraised on a scale of $0-10$, as indicated in Fig. 1. Replicate samples 14 and 15 resulted in ECP ratings of 5.5 and 6.0, respectively. A response scale based on ECPs, similar to this one, has been used in the past, ${ }^{9,10}$ although not as a response for a DOE process optimization. 


\begin{tabular}{|l||c||c||c||c|}
\hline \multicolumn{5}{|c|}{ Table l: Experimental Parameters } \\
\hline Sample No. & (Qual) & Temp & Flow & Fil Cur \\
\hline 1 & 3 & 250 & 30 & 13.5 \\
\hline 2 & 8 & 350 & 17.5 & 14.25 \\
\hline 3 & 9.5 & 250 & 5 & 13.5 \\
\hline 4 & 7.5 & 350 & 17.5 & 13.5 \\
\hline 5 & 0 & 450 & 5 & 13.5 \\
\hline 6 & 7 & 450 & 5 & 15 \\
\hline 7 & 10 & 450 & 5 & 15 \\
\hline 8 & 9.5 & 450 & 30 & 15 \\
\hline 9 & 9 & 350 & 5 & 14.25 \\
\hline 10 & 0 & 450 & 30 & 14.25 \\
\hline 11 & 0 & 250 & 17.5 & 14.25 \\
\hline 12 & 0 & 450 & 5 & 13.5 \\
\hline 13 & 1 & 250 & 30 & 15 \\
\hline 14 & 5.5 & 250 & 5 & 15 \\
\hline 15 & 6 & 250 & 5 & 15 \\
\hline 16 & 0 & 450 & 30 & 13.5 \\
\hline 17 & 9.5 & 350 & 30 & 13.5 \\
\hline 18 & 9.5 & 350 & 30 & 15 \\
\hline 19 & 8.5 & 350 & 17.5 & 14.25 \\
\hline 20 & 9.5 & 400 & 23.75 & 14.625 \\
\hline & & & & \\
\hline
\end{tabular}

Table II: Model Term Ranking: Transformed Quality

\begin{tabular}{lcccc} 
Model Term & Model & Coeffi- & Model Term & Model \\
Nerm & cient & & Term \\
Name & Range & Value & Effect & Rank \\
$(\mathrm{X} 1)^{2}$ & 1 & -1.826 & -1.826 & 1.00 \\
$\mathrm{X}^{*}{ }^{*}$ 3 & 2 & 0.850 & 1.701 & 0.93 \\
$(\mathrm{X} 3)^{2}$ & 1 & 1.185 & 1.185 & 0.65 \\
$\mathrm{X}^{*} \mathrm{X} 2$ & 2 & 0.441 & 0.883 & 0.48 \\
Fil Cur $(\mathrm{X} 3)$ & 1.5 & 0.564 & 0.846 & 0.46 \\
Flow $(\mathrm{X} 2)$ & 25 & -0.0299 & -0.747 & 0.41 \\
\hline
\end{tabular}

Characterization methods included stylus profilometry, electron channeling analysis, and TEM. ECP analysis was performed on a JEOL JSM-840 SEM. (Thin foils for TEM examination were prepared by dimple polishing and $5 \mathrm{kV} \mathrm{Ar}{ }^{+}$ion milling until electron transparency was achieved.) TEM examination was carried out on a Phillips CM30 TEM operating at $300 \mathrm{keV}$.

\section{RESULTS AND DISCUSSION}

For the sake of brevity we will just consider the limited optimization series indicated in Table 1, and for growth solely on lightly doped n-type substrates. As noted, we varied the filament and substrate temperatures, holding pressure and flow rate constant, during growth.

After the samples had been grown and characterized by their respective ECPs, the data were transformed and a model created in the CARD Analysis of Design Module along the lines of the discussion of DOE above. Table 2 shows the model terms after transformation into the nonlinear

temperature term with what we suppose to be a temperature-dependent thickness limit and/or a strong temperature dependence of $[\mathrm{H}]$ in the films. This term also carries the physics of changes in the surface reconstruction as a function of temperature.

The importance of filament temperature in the second, third, and fifth terms we attribute to the importance of cracking efficiency on the overall gas-phase and resultant surface-phase chemistries. Not only does the filament temperature determine the amounts of species produced, it also determines the stoichiometric ratios of species produced, further higher thermal velocities of gasphase species associated with higher filament temperatures can conceivably result in changes in gas-phase reactions. Finally, the flow terms, while not insignificant, do not play as dominant a role in the overall process. The diminished relative importance of the flow is something we have observed over the course of this work. A more detailed analysis of all these parameters should be forthcoming when we have completed all of our modeling efforts. 


\begin{tabular}{|l||c|}
\hline \multicolumn{2}{|l|}{ Table III: Error Data after Transform } \\
\hline Error \% & 2.47 \\
\hline Experimental Error $( \pm)$ & 0.187 \\
\hline $95 \%$ Confidence Limits $( \pm)$ & 0.521 \\
\hline Adj. R Square Lower Limit & 0.860 \\
\hline
\end{tabular}

Table 3 shows the error data for this analysis. The overall experimental error is a reasonable $2.4 \%$ after transform. Most of this error may have to do with filament memory effects. We have seen that when depositions are performed at lower filament temperatures, there can be a significant amount of W/Si alloying, resulting in a change in filament chemistries. This can manifest itself as changes in the film properties in a growth immediately following a low filament temperature deposition. Effects such as these could be evident in the data. Another source of experimental error must be due to this work being carried out in multi-use chamber, where contamination control is very difficult. In the end, however, the error statistics, including residual error statistics as well as the regression analysis, were good enough to warrant continuing.

Figs. 2 and 3 are the results of this analysis. Fig. 2 is the response surface and Fig. 3 is a verification of the predictive capability of our modeling, a comparison of various points on the response surface as measured by cross-sectional TEM. The TEM cross sections are labeled with letters from A-E, which correspond to points on the response surface. It is interesting and reassuring that only two of the samples shown in Fig. 3 are from the same optimization series that produced the response surface in Fig. 2. The agreement between TEM data and the model seems to indicate that the predictive capability of the model is independent of the particular data series from which the analysis is derived. It is fairly clear that Sample A is the best of the five samples studied. And when comparing the TEM cross sections of Samples E, D, and A with a line of constant substrate temperature, $350^{\circ} \mathrm{C}$, we see direct evidence of changes in growth morphology when varying the filament temperature at a fixed pressure, substrate temperature, and flow rate.

Numbers have been purposely left out of the plots because these values will differ for differing reactors, dopings, and thicknesses. Instead, we wished to emphasize trends.

At this point, we might begin to analyze this data, but to avoid unnecessary redundancy we will refer the interested reader to another presentation in this same proceeding. ${ }^{7}$

\section{Quality Response Surface}

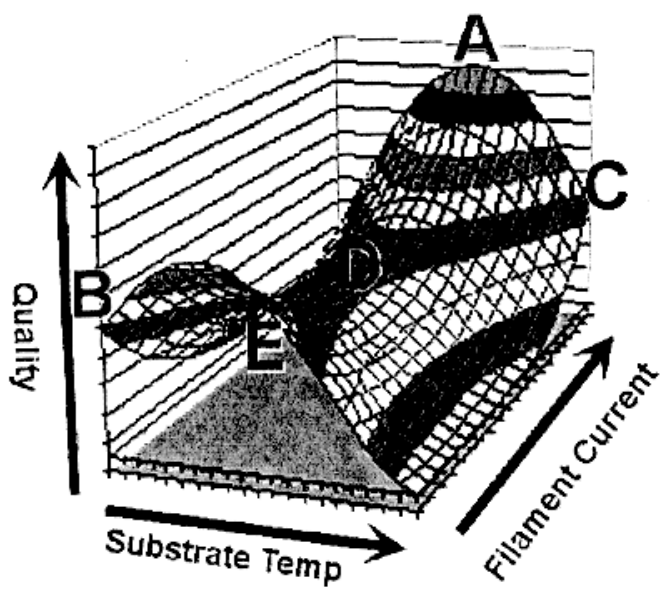

Figure 2. This is a graphical representation of the filament temperature, substrate temperature response surface for a fixed flow rate. Specific values on the axes have been omitted to indicate trends rather than numbers. Arrows point in direction of increasing values.

\section{CONCLUSIONS}

We have demonstrated the use of ECPs to perform a DOE process optimization. While the TEM evidence is hardly comprehensive, it is compelling that cross-sectional TEM analysis from independent experiments seems to confirm the predictive capability of this technique and the resultant model. Finally, we remark that the total work time to produce this analysis was approximately one week, including measurement with ECP, which was accomplished in one day for a truly large number of samples. This amount of time compares very favorably with the months required for more traditional analytical methods. Furthermore, it is questionable whether 


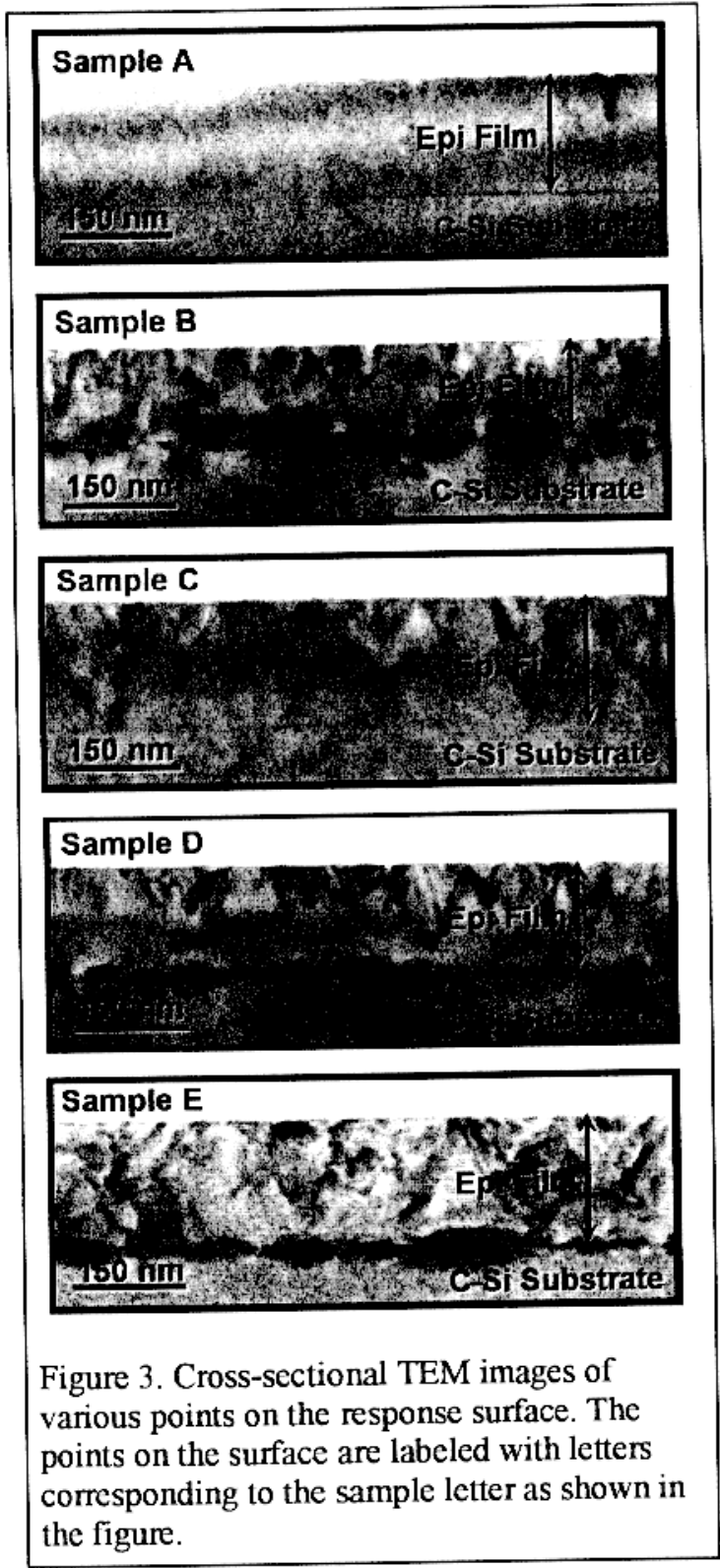

the points indicated as optimum would have been located if traditional methods had been used.

Certainly, one of the benefits of DOE is that it forces the experimentalist away from the usual or expected experiments and examines new data points.

\section{ACKNOWLEDGMENTS}

The authors wish to sincerely thank Alan Gallagher for many useful discussions. We would also like to thank the entire a-Si team for their support during this work. This work was supported by the United States Department of Energy under Contract No. DE-AC36-98GO10337.

\section{REFERENCES}

1. Brereton, R.G. Chemometrics - Application of mathematics and statistics to laboratory systems, $1^{\text {st }} \mathrm{Ed}$. West Sussex: Ellis Horwood, 1990.

2. Deming, S.N. and Morgan, S.L. Experimental design: a chemometric approach, $1^{\text {st }}$ Ed. N.Y. Elsevier, 1990. 3. Molenbroek, E. and Mahan, A. J. Applied Physics 82(4): 1909-1917, 1998.

4. Robertson, R. and Gallagher, A. J. Chem. Phys. 85(6):3623-3630, 1986.

5. Molenbroek, E. C. Thesis, University of Colorado. :1$159,1995$.

6. Thiesen, J. Iwaniczko, E. Mahan, H. Crandall, R. Jones, K. Reedy, R. and Matson, R. Submitted Appl. Phys. Lett., 1999.

7. Thiesen, J. Iwanikczo, E. Jones, K.M. Matson, R. Reedy, R. Mahan, H. and Crandall, R. MRS Spring Symp. V8.1. 1999

8. S-Matrix CARD for Windows. Eureka, Ca. S-Matrix Corp. (5), 1997.

9. Davidson, S.M. Nature 227:487-488, 1970.

10. Schulson, E.M. and Marsden, D.A. Radiation Effects 24:195-198, 1975. 


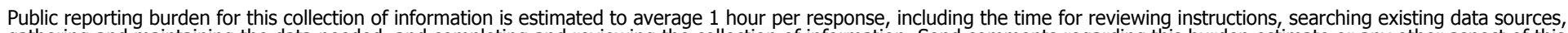

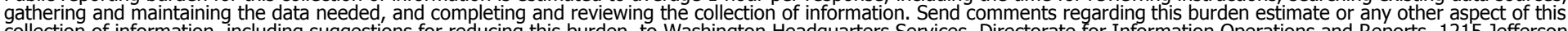

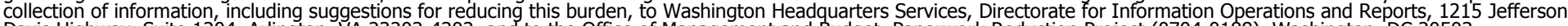

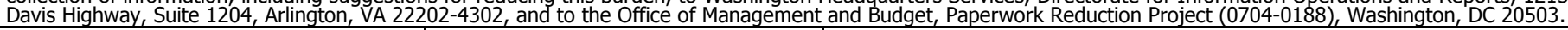

\begin{tabular}{|l|l|l|l|}
\hline 1. AGENCY USE ONLY (Leave blank) & $\begin{array}{l}\text { 2. REPORT DATE } \\
\text { August } 1999\end{array}$ & $\begin{array}{l}\text { 3. REPORT TYPE AND DATES COVERED } \\
\text { Conference Paper }\end{array}$ \\
\hline 4. TITLE AND SUBTITLE &
\end{tabular}

4. TITLE AND SUBTITLE

Use of Electron Channeling Patterns for Process Optimization of Low-Temperature Epitaxial

Silicon Using Hot-Wire Chemical Vapor Deposition

6. AUTHOR(S)

R. Matson, J. Thiesen, K.M. Jones, R. Crandall, E. Iwaniczko, and H. Mahan

7. PERFORMING ORGANIZATION NAME(S) AND ADDRESS(ES)

National Renewable Energy Laboratory

1617 Cole Blvd.

Golden, CO 80401-3393

9. SPONSORING/MONITORING AGENCY NAME(S) AND ADDRESS(ES)

5. FUNDING NUMBERS

$\mathrm{C}$ :

TA: PV902301

8. PERFORMING ORGANIZATION REPORT NUMBER

10. SPONSORING/MONITORING AGENCY REPORT NUMBER

CP-520-26364

11. SUPPLEMENTARY NOTES

12a. DISTRIBUTION/AVAILABILITY STATEMENT

National Technical Information Service

U.S. Department of Commerce

5285 Port Royal Road

Springfield, VA 22161

13. ABSTRACT (Maximum 200 words)

We demonstrate the first reported use of electron channeling patterns (ECPs) as a response for a statistical design of experiments processoptimization for epitaxial silicon. In an effort to fully characterize the new hot-wire chemical vapor deposition (HWCVD) method of epitaxial growth recently discovered at NREL, a large number of parameters with widely varying values needed to be considered. To accomplish this, we used the statistical design of experiments method. This technique allows one to limit the number of sample points necessary to evaluate a given parameter space. In this work we demonstrate how ECPs can effectively be used to optimize the process space as well as to quickly and economically provide the process engineer with absolutely key information.
14. SUBJECT TERMS
15. NUMBER OF PAGES
6

photovoltaics ; electron channeling patterns ; hot-wire chemical vapor deposition ;

16. PRICE CODE

\begin{tabular}{|c|c|c|}
\hline $\begin{array}{l}\text { 17. SECURITY CLASSIFICATION } \\
\text { OF REPORT } \\
\text { Unclassified }\end{array}$ & $\begin{array}{l}\text { 18. SECURITY CLASSIFICATION } \\
\text { OF THIS PAGE } \\
\text { Unclassified }\end{array}$ & $\begin{array}{l}\text { 19. SECURITY CLASSIFICATION } \\
\text { OF ABSTRACT } \\
\text { Unclassified }\end{array}$ \\
\hline
\end{tabular}

17. SECURITY CLASSIFICATION OF REPORT

NSN 7540-01-280-5500
Standard Form 298 (Rev. 2-89)

Prescribed by ANSI Std. Z39-18 